\title{
KARAKTERISTIK Bruguiera exarista Ding Hou YANG TUMBUH DI KECAMATAN SIBERUT UTARA MENTAWAI
}

\author{
Asroen \& Nursyahra \\ Program Studi Pendidikan Biologi \\ STKIP PGRI Sumatera Barat \\ Co. Author: \\ asroen2011a@gmail.com
}

\begin{abstract}
ABSTRAK
Karakter morfologi merupakan hasil ekspresi dari genetik dan lingkungan tempat tumbuhnya tumbuhan. Mangrove merupakan ekosistem yang dapat ditemukan di pinggir pantai berlumpur, muara sungai dan sebagian pantai berpasir. Tumbuhan yang hidup di hutan mangrove memperlihatkan perbedaan karakter morfologi antara satu lokasi tumbuh dengan lokasi lainnya. Dari beberapa buku sumber belum ditemukan ciri-ciri spesifik dari species tumbuhan Bruguiera exarista. Penelitian ini dilakukan di Hutan mangrove Siberut Utara kepulauan Mentawai dengan melakukan identifikasi terhadap species ini. Kemudian dibandingkan dengan data yang telah ada. Sampel diambil dengan teknik jelajah sepanjang hutan mangrove. Hasil penelitian menunjukkan terdapatnya perbedaan dan tambahan informasi tentang akar lutut dan terkadang berakar papan dengan warna akar coklat kemerahan berbintik kuning; batang utama berwarna putih kecoklatan; cabang tua berwarna putih kecokelatan dengan percabangan monopodial, buah berbentuk corong melingkar berwarna kuning pudar hingga kekuningan; hipokotil berbentuk bulat memanjang dengan warna hijau muda hingga kecoklatan; dengan ukuran panjang 2,7-3,4 cm; diameter 0,41-0,50 mm.
\end{abstract}

Key Word: Bruguiera, Mangrove, Mentawai, Siberut

\section{PENDAHULUAN}

Mangrove merupakan suatu ekosistem yang kompleks baik untuk tumbuhan maupun komunitasnya dan ada juga yang menyebutkan bahwa mangrove merupakan istilah umum untuk pohon yang hidup di daerah berlumpur, basah dan terletak di perairan pasang surut daerah tropis. Selain itu mangrove juga suatu vegetasi hutan yang tumbuh di antara garis pasang surut sehingga juga di sebut hutan pasang. Istilah-istilah mangrove baik digunakan untuk individu species tumbuhan maupun untuk komunitas pada habitat mangrove (Indryanto, 2006).

Species-species pohon utama yang menyusun suatu komunitas hutan mangrove salah satunya yaitu species familia dari Rhizophoraceae, kebanyakan ditemukan pada jalur yang dekat dengan laut atau zona terdepan (zona proksimal) yang terbentuk oleh species tumbuhan Avicennia, dan sonneratia. Species Rhizophoraceae ini merupakan komunitas mangrove yang paling khas terdapat di sepanjang pantai dan teluk- 
teluk yang tanjung. Species familia Rhizophoraceae dapat mencapai ketinggian 10-40 m bentuk batang dapat berupa pohon atau semak yang memiliki lenti sel pada bagian batangnya (Noor, Khazali, dan Suryadiputra, 2006). Familia Rhizophoraceae ini berkecambah di atas pohon sebelum jatuh di tanah (vivipar) hipokotilnya ada yang berbentuk silindris melengkung sampai silindris menyempit pada ujung hipokotilnya. Rhizophoraceae berkembang pada daerah lumpur berpasir, dari tingkat yang tergenang pada setiap pasang surut-naik sampai daerah yang tergenang hanya pada pasang purnama tertinggi dengan contoh genus penyusun hutan mangrove antara lain Rhizophora, ceriops dan Bruguiera (Nybakken, 1988; Rizki, dkk 2016)

Species tumbuhan pada familia ini juga banyak dimanfaatkan untuk kebutuhan obat misalnya Rhizophora apiculata yang dimanfaatkan oleh masyarakat untuk obat panas dalam, dengan cara meminum air rebusan daun tumbuhan ini. Species Bruguiera gymnorrhiza juga digunakan sebagai obat sakit perut dengan memanfaatkan daun, bunga dan buah tumbuhan ini (Rizki, \& Leilani, 2018)

Salah satu species dari Rhizophoraceae adalah Bruguiera exaristata Ding Hou. Sejauh ini tumbuhan tersebut belum diketahui nama daerah/lokalnya, tumbuhan ini perawakan berupa pohon atau semak dengan ketinggian mencapai $10 \mathrm{~m}$. Kulit kayu berwarna abu-abu tua, memiliki sejumlah besar akar nafas yang berbentuk akar lutut (Giessen, Wulffaat, Zieren, and Scholten, 2007). Daun berwarna hitam, bagian bawah memiliki bercak-bercak, tepi daun sering tergulung ke dalam. Letak daun berlawanan berbentuk bulat memanjang. ujung daun meruncing, panjang daun berukuran 5,5-11,5 lebar 2,5-4,5 cm, (Noor, dkk 2006). Bunga berwarna hijaukekuningan, berada di ketiak daun, yang menggantung. Letak bunganya soliter. Kalix berjumlah 8-10 berukuran panjang 10-15 mm, (Rosadi, 2013). Petal 8-10 berukuran panjang 10-13 mm. Hipokotil berbentuk tumpul, silindris agak menggelembung. Berukuran panjang 5-7 cm dan diameter 6-8 mm (Onrizal, 2008). Berdasarkan karakter morfologi dan keberadaan species ini yang terdapat di sepanjang pantai dan teluk-teluk tanjung Kepulauan Mentawai, oleh karena itu dilakukan penelitian tentang studi morfologi Bruguieara exaristata di hutan mangrove di Siberut Utara Kabupaten Kepulauan Mentawai

\section{BAHAN DAN METODE}

Alat yang akan digunakan dalam penelitian ini adalah, kamera digital, parang, meteran, gunting tanaman, tripleks, jarum jahit, kapter, oven, alat ukur mm, serta alat tulis dan buku identifikasi. sedangkan Bahan yang digunakan adalah kertas koran, kantong specimen/karong, lebel specimen, lakban, roll, kertas kalkir, mounting, tali rafia, benang jagung, alkohol $96 \%$, plastik ukuran $50 \mathrm{~kg}$ dan tumbuhan Rhizophoraceae.

Sebelum dilakukan pengambilan bahan koleksi, terlebih dahulu dilakukan penentuan jalur lokasi penelitian dengan jumlah 3 jalur lokasi, penentuan jalur lokasi ini dibuat secara vertikal pantai berdasarkan perbedaan zonasi dan kondisi daerah mangrove. Pada setiap jalur yang ditentukan diambil sebanyak 3 sampel secara acak. Hal ini bertujuan sebagai pembanding karakteristik species Rhizophoraceae. Sebelum pengambilan sampel di lapangan dilakukan pengamatan seperti pencatatan karakter tumbuhan Rizophoraceae yang meliputi habitat, habitus, dan warna. 
Setelah pengamatan dilakukan dilanjutkan dengan mengkoleksi tumbuhan. Sampel diambil sebanyak 3 rangkap (kecuali Akar) diberi label gantung yang diberi nomor koleksi. Setiap koleksi dimasukkan ke dalam lipatan koran, sampel ditumpuk dan diikat dengan menggunakan tali rafia. Kemudian disiram dengan menggunakan alkohol $96 \%$ sampai basah lalu disimpan di dalam kantong plastik yang tidak bocor berukuran $50 \mathrm{~kg}$ setelah itu dilakban dan dilapisi dengan tripleks berukuran 40 x $30 \mathrm{~cm}$ kemudian diikat kuat dengan menggunakan tali rafia. Pengeringan specimen di lakukan dengan cara manual yaitu dengan panas sinar matahari.

a. Pembuatan herbarium

Sampel yang telah benar-benar kering dijahitkan di atas kertas mounting dengan ukuran $30 \times 40 \mathrm{~cm}$, kemudian diberi label herbarium setelah itu herbarium tersebut di fotocopy dan digambarkan pada kertas kalkir (Rizki \& Des M 2019).

b. Penentuan dan Pengukuran Karakter Morfologi

Untuk mengetahui karakter morfologi suatu tumbuhan dilakukan pengamatan dan pengukuran terhadap karakter morfologi tumbuhan yang meliputi, akar, batang, daun, buah dan bunga. Pengamatan dan pengukuran pada akar meliputi: bentuk, tinggi, diameter, permukaan dan warna. Batang meliputi: warna (batang utama, cabang tua, cabang muda) bergetah/tidak, warna getah, arah tumbuh, arsitektur, tipe permukaan, percabangan, tinggi, diameter dan karakter lain. Daun meliputi: warna daun mudah, pucuk, dan tua (warna tangkai, tepi, pangkal ujung) filotaksis, kelengkapan, bentuk umum, pangkal, tepi dan ujung daun, pertulangan daun, permukaan atas bawah lebar dan panjang daun, bergetah/tidak, bentuk, panjang, permukaan atas bawah dan kedudukan. Buah meliputi tipe, warna, tnggal/majemuk bergetah/tidak. Bunga meliputi letak, macam, tipe bunga, kelengkapan bunga.

c. Identifikasi sampel

Kegiatan identifikasi ini dilakukan seperti, Mencocokan contoh tumbuhan yang dibawah dari lapangan dengan contoh spesimen tumbuhan yang ada diruang koleksi, Mencocokan atau menyamakan tumbuhan yang dibawa dari lapangan dengan gambar tumbuhan yang telah di publikasi atau diterbitkan (Des M, Rizki, \& Hidayati, 2018). Memperoleh informasi nama tumbuhan yang tepat melalui orang yang berpengalaman dan telah menguasai identifikasi tumbuhan. penentuan karakter morfologi ini menggunakan buku: Lawrence (1964) Giesen (2007), Yudianto (1992), Tjitrosoepomo (2003), Noor dkk (2006).

d. Analisis data

Data yang telah didapatkan dari hasil observasi di lapangan dideskriptif melalui studi kepustakaan dituliskan dalam bentuk tabel di mana pada tabel ini akan dicantumkan karakter morfologi tumbuhan yang meliputi akar, batang, daun, buah dan bunga yang telah ditentukan. Kemudian hasil deskripsi variasi morfologi yang didapat dari penelitian dibandingkan dengan informasi yang telah ada sebelumnya. 


\section{HASIL DAN PEMBAHASAN}

Bruguiera exaristata Ding Hou memiliki akar lutut dan terkadang berakar papan dengan warna akar coklat kemerahan berbintik kuning; batang utama berwarna putih kecoklatan; cabang tua berwarna putih kecokelatan dengan percabangan monopodial; tinggi 16,0-17,2 $\mathrm{m}$; diameter batang 10,9-13,06 cm; dan berbentuk elipslonjong; ukuran daun tua 5,7-7 x 2,5-3 cm; daun muda 6,6-7 x 2,9-3,4 cm; panjang tangkai daun tua 1,4-1,7 cm; tangkai daun muda 1,4-2 cm; bunga berkelompok 2-3 kelompok bunga; kelopak berjumlah 10 sepal berwarna hijau muda hingga kuning pudar; mahkota berjumlah 10 petal dengan warna putih cream; buah berbentuk corong melingkar berwarna kuning pudar hingga kekuningan; hipokotil berbentuk bulat memanjang dengan warna hijau muda hingga kecoklatan; dengan ukuran panjang 2,7-3,4 $\mathrm{cm}$; diameter 0,41-0,50 mm. Untuk deskripsi lebih lengkapnya dapat dilihat pada tabel 1 .

Tabel 1. Perbedaan dan persamaan karakter morfologi Bruguiera exaristata Ding Hou di hutan mangrove kecamatan siberut utara kabupaten kepulauan Mentawai dan perbandingan data dengan informasi sebelum penelitian

\begin{tabular}{|c|c|c|c|}
\hline \multirow{2}{*}{ NO } & $\begin{array}{l}\text { KARAKTER } \\
\text { MORFOLOGI }\end{array}$ & Deskripsi Bruguieara exaristata & Sumber referensi* \\
\hline & 1 & 2 & 3 \\
\hline \multirow[t]{5}{*}{1} & Akar & & \\
\hline & Bentuk akar & Lutut melebar pada bagian pangkal & Lutut $^{1}$ \\
\hline & Warna akar & Coklat keabu-abuan belenti sel kecil & Abu-abu tua ${ }^{3}$ \\
\hline & Bergetah/tidak & Bergetah & - \\
\hline & Warna getah & Bening & - \\
\hline \multirow[t]{17}{*}{2} & Batang & & \\
\hline & Bentuk batang utama & Bulat (teres) & - \\
\hline & Bentuk cabang muda & Bulat (teres) & - \\
\hline & Bentuk cabang tua & Bulat (teres) & - \\
\hline & Percabangan & Monopodial & Monopodial $^{7}$ \\
\hline & Permukaan & Kasar belenti sel kecil & Kasar $^{3}$ \\
\hline & Arah tumbuh & Tegak lurus (erectus) & - \\
\hline & Bergetah/tidak & Bergetah & - \\
\hline & Tinggi & $16,0-17,0 \mathrm{~m}$ & $10 \mathrm{~m}^{3}$ \\
\hline & Diameter & $10,9-13,06 \mathrm{~cm}$ & - \\
\hline & Warna batang utama & Abu-abu kecoklatan & Abu-abu tua ${ }^{4}$ \\
\hline & 1 & 2 & 3 \\
\hline & Warna cabang muda & Abu-abu kecoklatan-coklat & - \\
\hline & Warna cabang tua & Coklat muda, coklat keabu-abuan & - \\
\hline & Warna ruas & Keputih-putihan, keabu-abuan & $A b u-a b u^{3}$ \\
\hline & Warna buku & Abu-abu kecoklatan & - \\
\hline & Karakter lain & Batang berbintik-bintik kuning & Pangkal batang menonjol $^{7}$ \\
\hline \multirow[t]{5}{*}{3} & Daun & & \\
\hline & Bentuk umum daun & Elips membulat & Bulat memanjang $^{1}$ \\
\hline & Kelengkapan daun & Tidak lengkap & - \\
\hline & Macam/ filotaksis & Berhadapan & Berlawanan $^{3}$ \\
\hline & Bentuk pangkal daun & $\begin{array}{l}\text { Meruncing } \\
\text { (acuminatus) }\end{array}$ & - \\
\hline
\end{tabular}




\begin{tabular}{|c|c|c|c|}
\hline & Bentuk tepi daun & Rata (intiger) & - \\
\hline & Bentuk ujung daun & $\begin{array}{l}\text { Meruncing } \\
\text { (acuminatus) }\end{array}$ & $\begin{array}{l}\text { Meruncing } \\
\text { (acuminatus) }^{6}\end{array}$ \\
\hline & Pertulanagan daun & Menyirip (penninervis) & Menyirip (penninervis) \\
\hline & Tipe daun & Tunggal & - \\
\hline & Bergetah/tidak & Bergetah & - \\
\hline & Warna pucuk & Kekuningan, kuning muda & - \\
\hline & Warna daun tua & Hijau mengkilap, hijau muda & Hijau pekat ${ }^{4}$ \\
\hline & Warna permukaan atas & Hijau mengkilap, hijau muda & - \\
\hline & $\begin{array}{l}\text { Wrna permukaan } \\
\text { bawah }\end{array}$ & Hijau kekuningan, hijau muda & - \\
\hline & Warna tangkai tua & Hijau muda, hijau kekuningan & - \\
\hline & $\begin{array}{l}\text { Warna permukaan atas } \\
\text { tangkai tua }\end{array}$ & Hijau kekuningan & - \\
\hline & $\begin{array}{l}\text { Warna permukaan } \\
\text { bawah tangkai tua }\end{array}$ & Hijau muda, kekuningan & - \\
\hline & Panjang daun tua & $10,5-13,2 \mathrm{~cm}$ & $5,5-11,5 \mathrm{~cm}^{6}$ \\
\hline & Lebar daun tua & $4,9-6 \mathrm{~cm}$ & $2,5-4,5 \mathrm{~cm}^{7}$ \\
\hline & Panjang tangkai tua & $2,7-3,9 \mathrm{~cm}$ & - \\
\hline & Diameter tangkai & $0,2-0,4 \mathrm{~mm}$ & - \\
\hline & Warna daun muda & Kuning muda, hijau muda & - \\
\hline & $\begin{array}{l}\text { Warna permukaan atas } \\
\text { daun muda }\end{array}$ & Kuning muda, hijau kekuningan & - \\
\hline & $\begin{array}{l}\text { Warna permukaan } \\
\text { bawah daun muda }\end{array}$ & Hijau muda, kehijauan & - \\
\hline & Warna tangkai muda & Hijau muda, hijau kekuningan & - \\
\hline & $\begin{array}{l}\text { Warna permukaan atas } \\
\text { tangkai muda }\end{array}$ & Hijau muda hijau kekuningan & Hijau muda ${ }^{6}$ \\
\hline & $\begin{array}{l}\text { Warna permukaan } \\
\text { bawah tangkai muda }\end{array}$ & Hijau muda, hijau kekuningan & Hijau muda-hijau tua ${ }^{4}$ \\
\hline & Panjang daun muda & $8,5-9,7 \mathrm{~cm}$ & - \\
\hline & Lebar daun muda & $3,6-4,4 \mathrm{~cm}$ & - \\
\hline & Panjang tangkai muda & $1,7-2,2 \mathrm{~cm}$ & - \\
\hline & Diameter tangkai & $0,2-0,3 \mathrm{~mm}$ & - \\
\hline 4 & Bunga & & \\
\hline & Macam & Berkelompok 3-4 kelompok bunga & $\begin{array}{l}\text { Berkelompok 3-4 kelompok } \\
\text { bunga }^{1}\end{array}$ \\
\hline & Letak & Soliter & Soliter $^{3}$ \\
\hline & Kelopak (kalix) & & \\
\hline & Bentuk & Melengkung & - \\
\hline & Warna permukaan atas & Kemerahan, hijau kemerahan & Merah mudah ${ }^{1}$ \\
\hline & 1 & 2 & 3 \\
\hline & $\begin{array}{l}\text { Warna pemukaan } \\
\text { bawah }\end{array}$ & Kuning kemerahan & - \\
\hline & $\begin{array}{l}\text { Jumlah sepal } \\
\text { Mahkota (corolla) }\end{array}$ & 8-10 sepal & $8-10$ sepal $^{1}$ \\
\hline & Bentuk & Melengkung kedalam & $\begin{array}{l}\text { Tombak berambut putih } \\
\text { dibagian pinggir }{ }^{4}\end{array}$ \\
\hline & Warna & Kuning pucat, keabu-abuan & Putih $^{1}$ \\
\hline & Jumlah petal & $8-10$ petal & $8-10$ petal $^{3}$ \\
\hline
\end{tabular}




\begin{tabular}{llll}
\hline 5 & Buah & & \\
\hline & Bentuk & tabung tumpul & $\begin{array}{l}\text { Tumpul } \\
\text { mengelembung }\end{array}$ \\
& Harna & Hijau, keunguan, kuning kemerahan & Hijau keunguan \\
& & \\
Diameter & $0,35-0,57 \mathrm{~mm}$ & - & \\
Bergetah/tidak & Bergetah & - & \\
Warna getah & Bening & - & \\
Tunggal/majemuk & Tunggal & Tunggal $^{6}$ & \\
Permukaan & Halus beruas & & \\
Warna hipokotil & Hijau tua, hijau muda & Hijau muda keunguan $^{3}$ \\
Bentuk hipokotil & Silindris tumpul & Silindris tumpul & \\
Panjang hipokotil & $8-11,9 \mathrm{~cm}$ & $5-7 \mathrm{~cm}^{1}$ & \\
Diameter hipokotil & $0,41-0,50 \mathrm{~mm}$ & $6-8 \mathrm{~mm}^{3}$ \\
\hline
\end{tabular}

*Sumber:Gissean $(2007)^{1}$, Noor dkk $(2006)^{3}$,Sutarno $(2002)^{4}$, Rosadi $(2013)^{6}$, L. Catherin $(1993)^{7}$

Bruguiera exaristata Ding Hou memiliki akar lutut dan terkadang berakar papan dengan warna akar coklat kemerahan berbintik kuning; batang utama berwarna putih kecoklatan; cabang tua berwarna putih kecokelatan dengan percabangan monopodial; tinggi 16,0-17,2 m; diameter batang 10,9-13,06 cm; dan berbentuk elipslonjong; ukuran daun tua 5,7-7 x 2,5-3 cm; daun muda 6,6-7 x 2,9-3,4 cm; panjang tangkai daun tua 1,4-1,7 cm; tangkai daun muda 1,4-2 cm; bunga berkelompok 2-3 kelompok bunga; kelopak berjumlah 10 sepal berwarna hijau muda hingga kuning pudar; mahkota berjumlah 10 petal dengan warna putih cream; buah berbentuk corong melingkar berwarna kuning pudar hingga kekuningan; hipokotil berbentuk bulat memanjang dengan warna hijau muda hingga kecokelatan; dengan ukuran panjang 2,7-3,4 cm; diameter 0,41-0,50 $\mathrm{mm}$.

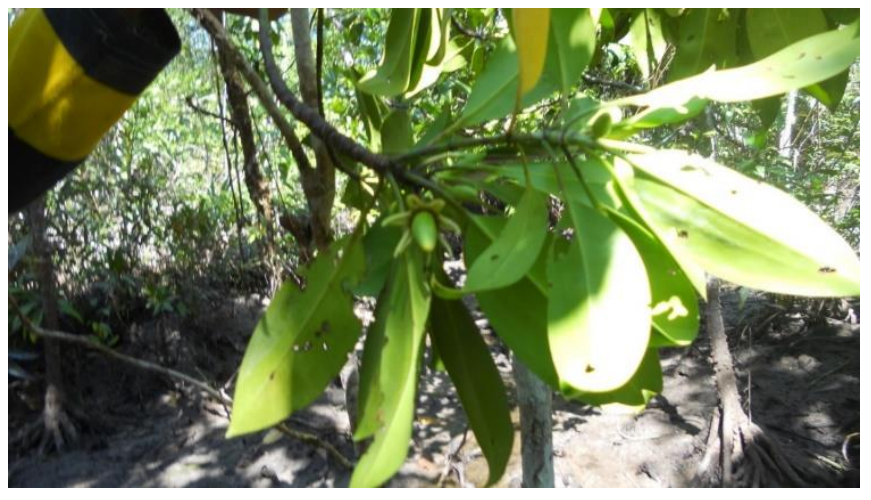

Gambar 1. Foto Species Bruguiera exaristata

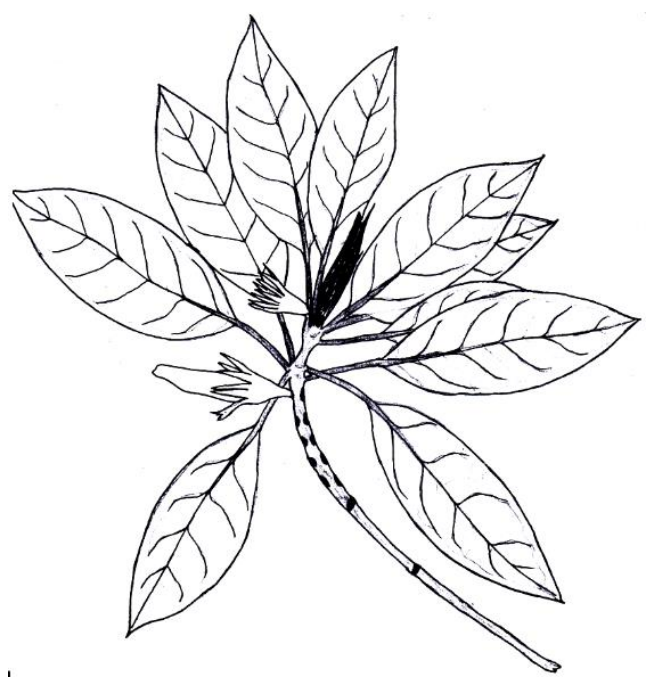

Gambar 2. Sketsa Herbarium Species Bruguiera exaristata 


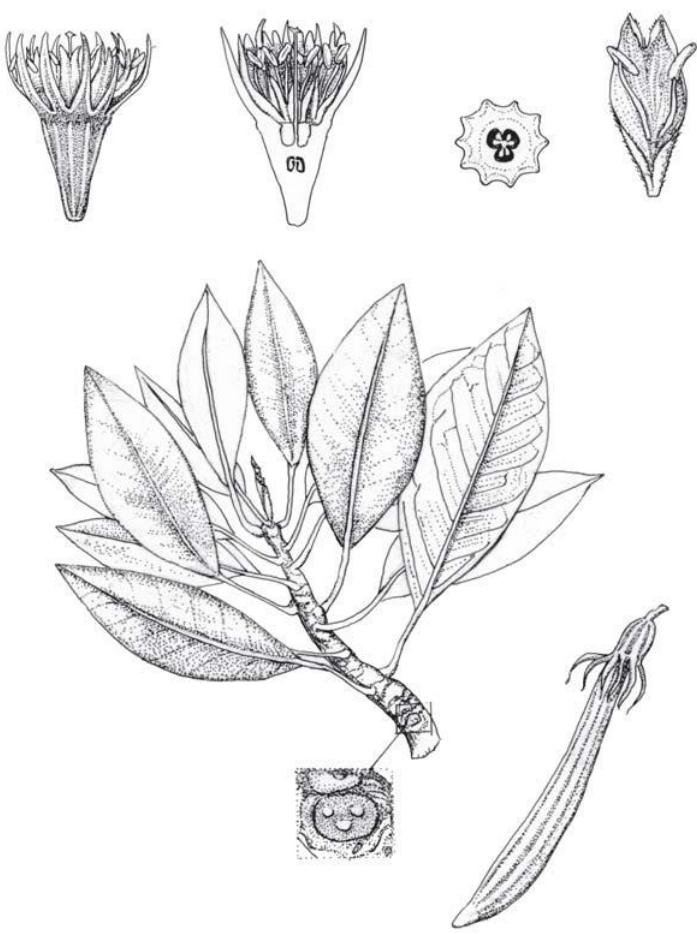

Gambar 3. Struktur morfologi tumbuhan Bruguieara exaristata Ding Hou (Giesen, 2007)

Species tumbuhan ini ditemukan pada daerah belakang hutan mangrove yang mengelompok hanya jenis tersebut dengan kondisi substratnya tanah liat dan berpasir. Kemampuan tumbuhnya species tumbuhan pada kondisi tanah liat yang berpasir membuat species tumbuhan ini memiliki karakter morfologi yang berbeda tarutama pada ukuran tinggi batang, daun serta hipokotil. Sedangkan menurut Noor dkk (2006), dan Gissean (2007), serta Onrizal (2008), mengatakan bahwa tumbuhan jenis ini memiliki ketinggian 9-10 $\mathrm{m}$ dengan ukuran daun 5,5-11,5 x 2,5-4,5, hipokotil berbentuk silindris tumpul agak menggelembung berwarna hijau muda dengan ukuran panjang 5-7 cm dan diameter 6-8 $\mathrm{mm}$. Adanya perbedaan karakter tumbuhan ini disebabkan oleh perbedaan kondisi substrat di mana jenis tumbuhan ini tumbuh di sepanjang jalur air yang menuju bagian belakang dan kadangkadang ditemukan pada daerah pertengahan hutan mangrove yang substratnya berlumpur serta toleran terhadap salinitas yang tinggi.

\section{KESIMPULAN}

Berdasarkan penelitian yang telah dilakukan dapat disimpulkan bahwa, terdapatnya beberapa perbedaan morfologi antara Bruguiera exaristata yang ditemukan di hutan mangrove Mentawai dengan daerah lain yang telah dipublikasi sebelumnya, perbedaan itu dapat terlihat pada organ akar, batang, daun dan bunga.

\section{DAFTAR PUSTAKA}

Indryanto. 2006. Ekologi Hutan. Jakarta: PT Bumi Aksara.

Des, M., Rizki, R., \& Hidayati, H. (2018, April). Ethnobotany in Traditional Ceremony at Kanagarian Sontang Cubadak Padang Gelugur Subdistrict, Pasaman District. In IOP Conference Series: Materials Science and Engineering (Vol. 335, No. 1, p. 012018). IOP Publishing. Noor Y. R, M. Khazali, dan I. N. N. Suryadiputra. 2006. Panduan Pengenalan Mangrove Di Indonesia. Institut Pertanian Bogor.

Nybakken, W.James. 1988. Biologi Laut

Suatu Pendekatan Ekologis. Jakarta: PT Gramedia

Giessen. W, S. Wulffraat, M. Zieren, and L. Scholten. 2007. Mangrove 
Guidebook For Southeast Asia. FAO and Wetland International: Thailand.

Rizki, R., Safitri, E., \& Asroen, A. (2016). Morfologi Bruguiera Cylindrica (L.) Blume Yang Tumbuh Di Hutan Mangrove Kecamatan Siberut Utara Kabupaten Kepulauan Mentawai. Sainstek: Jurnal Sains dan Teknologi, 7(1), 26-32.

Rizki, R., \& Leilani, I. (2018). Etnofarmakologi Tumbuhan Familia Rhizophoraceae oleh Masyarakat di Indonesia. Jurnal Bioconcetta, 3(1).

Rizki, R., \& Novi, N. (2017). Respon Pertumbuhan Bibit Mangrove Rhizophora Apiculata B1 pada Media Tanah Topsoil. Jurnal Bioconcetta, 3(2).

Rizki, R., \& M, D. (2019, November 1).

Teknik Pengumpulan Data Sampel Tumbuhan Untuk Pembuatan Spesimen Herbarium.

https://doi.org/10.17605/OSF.IO /4AU8K

Rosadi, A., Sahad, M., Budi, I. 2013. Karakterisasi Dan Kekerabatan Tumbuhan Mangrove

Rhizophoraceae Berdasarkan Morfologi, Anatomi Dan Struktur Luar Serbuk Sari.Jurusan Biologi FMIPA UNPAD: PTNBR - BATAN Bandung Sumedang.

Onrizal. 2008. Panduan Pengenalan Dan Analisis Vegetasi Hutan Mangrove. Departemen

Kehutanan, Fakultas Pertanian: Universitas Sumatera Utara.
Lawrence, G. H. M. 1968. Taxonomy of Vascular Plants. The Mc millan Company, New York.

Sudarmadji. 2004. Deskripsi Jenis-jenis Anggota Suku Rhizophoraceae di Hutan Mangrove Taman Nasional Baluran Jawa Timur. Journal Biodiversitas.Jurusan Biologi FMIPA Universitas Jember. 